appropriate for journal publication, too long to appear under Section News and too specialized to be carried as Eos feature articles. On the other hand, it would represent still another arrival in a continually increasing incoming mail load, would still (given the wide range of interests in our section) have a requirement for broad appeal, and might tend to isolate the rest of the Union from the interesting things going on in ocean research.

Feelings on this topic have not yet crystallized within the Executive Committee: some members lean toward giving it a try, others feel we already have an adequate range of options. We would like to hear from our Eos readers. Please send your comments via Telemail to OC.EXEC, or by fax to me at 619-534-6849.-Fred Spiess, Scripps Institution of Oceanography

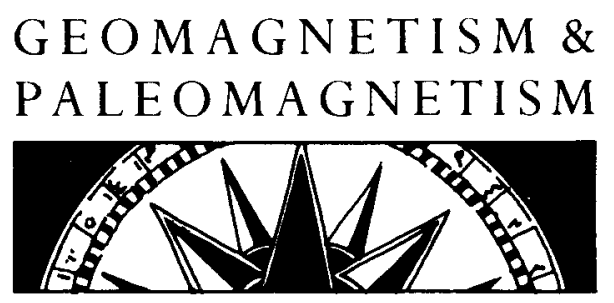

Editor: Kenneth P. Kodama, Department of Geology, Williams Hall \#31, Lehigh University, Bethlehem, PA 18014; tel. 215-758-3663

\section{Fennoscandia Paleomagnetics Meeting}

\section{PAGE 252}

In a repeat of a 1986 meeting of paleomagnetists from Scandinavia (EOS, October 27,1987 ), a second meeting was held Octo- ber 26 to November 2, 1990, in Luleå, Swe: den, to discuss recent developments in the Precambrian data base for Fennoscandia and other continents of interest, such as the Ukraine Block and the Gondwana continents.

The meeting was essentially a 9-day workshop: participants compiled, computed, and plotted, with 1 day reserved for formal presentations. In addition to host Sten Åke Elming of Lulea, the following scientists attended: L. J. Pesonen, S. Mertanen, M. Leino, J. Marmo (Finland); N. Abrahamsen (Denmark); G. Bylund, R. Gorbatschev, G. Vidal (Sweden); E. Halvorsen, M. Smethurst, T. Torsvik (Norway); A. N. Khramov, A. Krasnova, N. P. Michailova (U.S.S.R.); T. Onstott (U.S.); and R. Van der Voo (U.S./Spain).

The focus of the meeting was to integrate the Precambrian paleopoles from the Baltic Shield (Fennoscandia and adjacent Karelia in the U.S.S.R.) with those from the Ukraine Block. In addition, a first attempt was made to compile Precambrian Gondwana data and to compare these (without much immediate success) with the northern European results. The data from the Ukraine Block and the Baltic Shield are in general agreement, although not all Ukrainian results are dated precisely enough to permit detailed conclusions.

The success of the meeting was considerably enhanced by the availability of nearly as many personal computers as scientists. Each computer was loaded with a copy of the GMAP program of $T$. Torsvik and $M$. Smethurst, which includes several options, including a paleopole data base. This allows the possibility to extract paleopole files from a data base, which in turn can be rotated about Euler poles, filtered, selected by time or spatial coordinates, and graphically displayed. Apparent Polar Wander Paths can be constructed using the cubic spline method of J. Kent and colleagues. R. Van der Voo demonstrated the ORACLE data base management program and the paleopole data base compiled by M. W. McElhinny and J. Lock of Gondwana Consultants (Australia), who had sent their most up-to-date data compilation.

A special issue of Precambrian Research may result from this meeting, with Precambrian paleomagnetic contributions from several participants. A future meeting is planned for 1994 in Trondheim, Norway, where attention will focus on integration and comparisons with North American results.-Lauri $J$. Pesonen, Geological Survey of Finland, Espoo; Rob Van der Voo, Instituto Jaume Alm era, Barcelona, and University of Michigan, Ann Arbor

\section{Weston Observatory Resumes Operation}

PAGE 252

Weston Observatory, the geophysical research facility of Boston College, announces that it has resumed operation of its geomagnetic observatory. A three-component fluxgate magnetometer produced by the University of California, Los Angeles, has been installed in the geomagnetic observatory building. The data are sampled at 10-s inter vals and averaged over 1 -min periods. The microcomputer controlling data acquisition is linked into Boston College's Geoscience Computing Network, an internet node. Data will be submitted to the National Oceanic and Atmospheric Administration's National Geophysical Data Center under the reference code "B."

For additional information, contact Robert D. Regan, Weston Observatory, 381 Concord Rd., Weston, MA 02193; tel. 617-899. 0950 . 